\title{
Neonatal outcomes in relation to sex differences: a national cohort survey in Taiwan
}

\author{
Yi-Hao Weng ${ }^{1}$, Chun-Yuh Yang ${ }^{2}$ and Ya-Wen Chiü $^{3 *}$
}

\begin{abstract}
Background: An extensive assessment investigating the association between sex differences and neonatal outcomes is lacking. In the current study, we estimated the correlation of gender with adverse birth outcomes in a large cohort population.

Methods: National population-based data containing maternal and neonatal information in 2001 to 2010 were derived from the Health Promotion Administration, Taiwan. Singletons without high-risk pregnancy were further analyzed for the sex ratio of live births in relation to neonatal outcomes-including preterm birth, birth weight, neonatal death, delivery mode, and congenital anomaly. A multivariate logistic regression model was used to adjust for possible confounders.

Results: In total, 2,123,100 births were valid for the analysis. Overall, the sex ratio at birth (male/female) was 1.096. Compared to multiple births, the sex ratio was significantly higher with singleton births $(p<0.001)$. Among multiple births, the incidence of stillbirths was significantly higher in males than in females $(p<0.05)$. The sex ratio at gestational age (GA) <37 weeks was 1.332, and it declined proportionally with a rise in the GA to 0.899 at GA of $\geq 41$ weeks. In contrast, the sex ratio was 0.850 at birth weight $<3000 \mathrm{~g}$, and it rose proportionally with a rise in the birth weight to 1.902 at birth weight $\geq 4000 \mathrm{~g}$ (macrosomia). Operative delivery was more common in males than in females $(p<0.001)$. The regression analysis showed greater risks of preterm birth, macrosomia, operative delivery, neonatal death, and congenital anomaly among male newborns.

Conclusions: Male gender carried higher risks of adverse neonatal outcomes, including preterm birth, macrosomia, operative delivery, neonatal death, and congenital anomaly. The data have clinical implications on health surveillance for plotting strategies in response to the unbalanced sex ratio in relation to the boy preference.
\end{abstract}

Keywords: Sex ratio, Gender, Cesarean section, Birth weight, Gestational age, Birth outcome, Congenital anomaly

\section{Background}

Males at birth outnumber females throughout the world [1]. The average sex ratio at birth, defined as the ratio of newly born male to female neonates in a population, is around 1.05 [2]. The sex ratio is associated with a variety of factors. The maternal age or birth order may alter the sex ratio at birth [2-5]. In addition, nutritional deprivation or exposure to certain chemicals during pregnancy may lead to a decline in the sex ratio at birth $[6,7]$. The

\footnotetext{
* Correspondence: bettychiu@tmu.edu.tw

${ }^{3}$ Master Program in Global Health and Development, Health Policy and Care Research Center, College of Public Health and Nutrition, Taipei Medical University, 250 Wu-Hsing Street, Taipei 110, Taiwan

Full list of author information is available at the end of the article
}

hypothesis of these alternations is that male fetuses are more vulnerable to environmental stimulation [8-12]. Socioeconomic parameters, such as a preference for boys, are also regarded as important reasons influencing the sex ratio [13]. With the advance of assisted reproductive technologies, sex-selective abortions have been blamed as a major factor causing gender inequity at birth $[14,15]$.

Although a number of studies investigated the association between sex differences and adverse pregnancy outcomes [16-18], little research has focused on correlations of the sex ratio at birth with neonatal conditions [4]. It is not clear whether a change in the sex ratio may have impacts on neonatal outcomes. In this retrospective 
cohort study, we explored nationwide population-based data of over 2 million births. Our results provide clinical implications of outcomes in relation to the sex at birth.

\section{Methods}

\section{Data source}

The targets of this population-based study were all births from 1 January 2001 to 31 December 2010 in Taiwan. Maternal and neonatal data were derived from the birth notification system, a database established by the Health Promotion Administration, Ministry of Health and Welfare, Taiwan [19]. Medical organizations and midwives have to report all births to this system via an online reporting system within 7 days. If there are changes in the reported data, revisions via the online reporting system are mandatory within 60 days. The Health Promotion Administration provided maternal and neonatal data and approved the use in this study. The study protocol was approved by the Research Ethics Committee of the National Health Research Institutes in Taiwan. All records of participants were anonymized and de-identified prior to analysis.

\section{Neonatal outcomes}

Neonatal outcomes were assessed by the following seven parameters: multiple birth, stillbirth, neonatal death, congenital anomaly, gestational age (GA), delivery mode, and birth weight (low birth weight and macrosomia). Stillbirth was defined as the death of a fetus in the $\geq 20$ th week of gestation [20]. Congenital anomaly included any major abnormality of the central nervous, craniofacial, cardiovascular, digestive, urogenital, musculoskeletal, respiratory systems, or chromosome. Minor anomaly, such as a skin tag, was not recorded in this database. Preterm birth was defined as GA $<37$ weeks. Delivery mode was classified into cesarean section (CS) and vaginal delivery. Operative delivery was defined as delivery mode of either CS or vaginal delivery with the use of forceps or vacuum. Low birth weight was defined as a birth weight $<2500$ g. Macrosomia was defined as a birth weight $\geq 4000$ g.

\section{Population for analyses}

All births with an identified gender were included when estimating correlations of the sex ratio with stillbirths and multiple births. Otherwise, cases of stillbirths, high risk pregnancy, or multiple births were excluded when measuring correlations of the sex ratio with the following five outcomes: GA, birth weight, neonatal death, congenital anomaly, and delivery mode. High-risk pregnancy was defined as maternal conditions that threaten the health or life of the mother or her fetus, such as anemia (hematocrit $<30 \%$ or hemoglobin $<10 \mathrm{~g} / \mathrm{dL}$ ), cardiac disease, pulmonary disease, diabetes, syphilis, polyhydramnios (amniotic fluid index (AFI) $\geq 24 \mathrm{~cm}$ or deepest vertical pool (DP) $\geq 8 \mathrm{~cm}$ ) or oligohydramnios (AFI $\leq 5 \mathrm{~cm}$ or DP $\leq 1 \mathrm{~cm}$ ), hemoglobinopathy, chronic hypertension, pregnancy-induced hypertension, toxemia, pre-eclampsia, cervical incompetence, $\mathrm{Rh}$ disease, renal disease, having a preemie or a baby with birth weight $\geq$ $4000 \mathrm{~g}$ or $<2500 \mathrm{~g}$.

\section{Statistical analyses}

Statistical analyses were conducted using a commercially available program (SPSS 19.0 for Windows, SPSS, Chicago, IL, USA). We first applied a chisquared test to determine whether sex ratio was associated with neonatal outcomes-including GA, birth weight (low birth weight and macrosomia), neonatal death, congenital anomaly, and delivery mode (CS vs. vaginal delivery) $[4,16-18,21]$. Further, we selected potential confounders a priori and included them into the analytic model. A multivariate logistic regression model was used to estimate the risk of neonatal birth outcomes in relation to the sex ratio after adjusting for possible confounders. Factors associated with sex ratio in the univariate analysis were used as confounders for the multivariate logistic regression analysis. Significance was defined as $p<0.05$. The odds ratio (OR) and $95 \%$ confidence intervals $(\mathrm{CI})$ were expressed after adjusting for the control variables.

\section{Results}

Data on 2,123,781 births were collected in Taiwan from 2001 to 2010 (Fig. 1). We excluded 681 births with unidentified sex (ambiguous gender) and incomplete data, leaving 2,123,100 births for the analysis, including 1,109,989 males and 1,013,111 females (sex ratio at birth $($ male/female $)=1.096)$. Almost universal deliveries were accomplished by obstetricians in hospitals (68.14\%) and obstetric clinics (31.72\%). Only very few births were achieved by midwives $(0.04 \%)$, at home $(0.08 \%)$, or at other places $(0.02 \%)$.

\section{Multiple births}

The sex ratios were $1.096,1.076,1.065$, and 0.733 for singletons, twins, triplets, and quadruplets, respectively. When compared to multiple births, the sex ratio was significantly higher for singleton births $(p<0.001)$ (Fig. 2).

\section{Stillbirths}

The incidences of stillbirths were $0.88,2.89,4.34$, and $11.54 \%$ among singletons, twins, triplets, and quadruplets, respectively. Among multiple births, the incidence of stillbirths was significantly higher in males than 


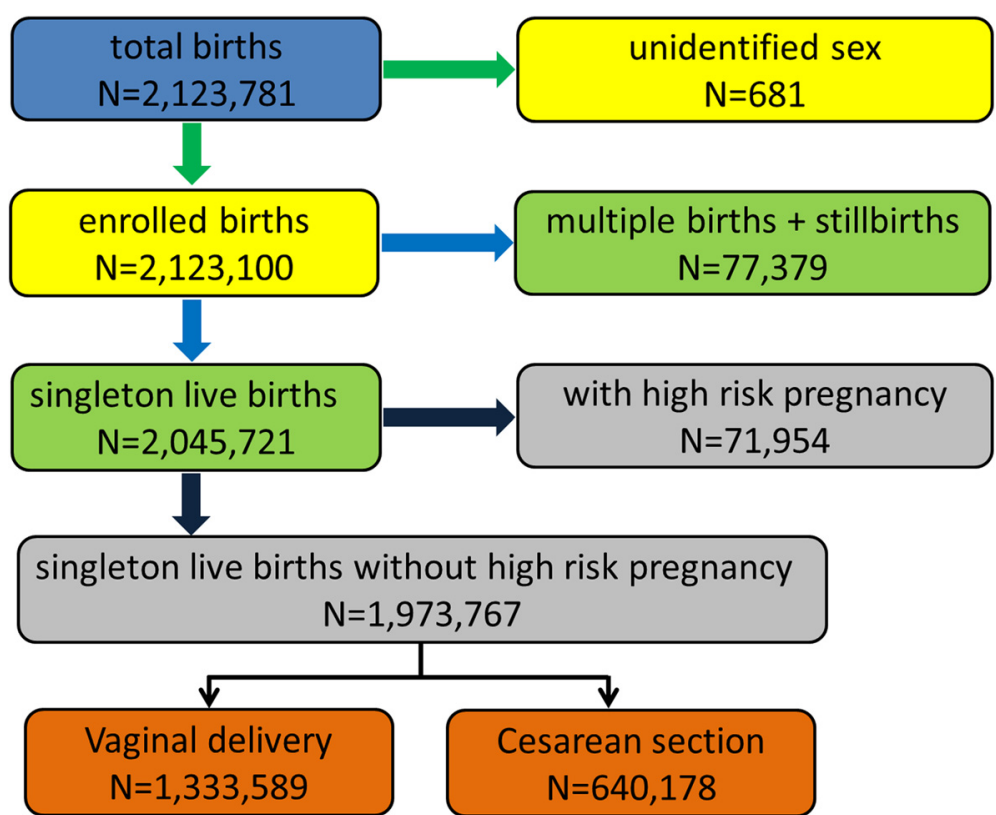

Fig. 1 Assembly of study sample

females $(p<0.05)$ (Fig. 3). In contrast, there was no significant difference in the incidence of stillbirths between males and females among singletons.

\section{Singleton live births without high-risk pregnancy}

In total, there were 2,045,721 singleton live births. We excluded 71,954 births with high-risk pregnancy, leaving a total of 1,973,767 births for further analysis (Fig. 1).

\section{$G A$}

The sex ratio among singleton live births without highrisk pregnancy was 1.096. There was a significant correlation of the sex ratio with GA (Table 1). The sex ratio was 1.356 for preterm birth, and it proportionally declined

\section{sex ratio}

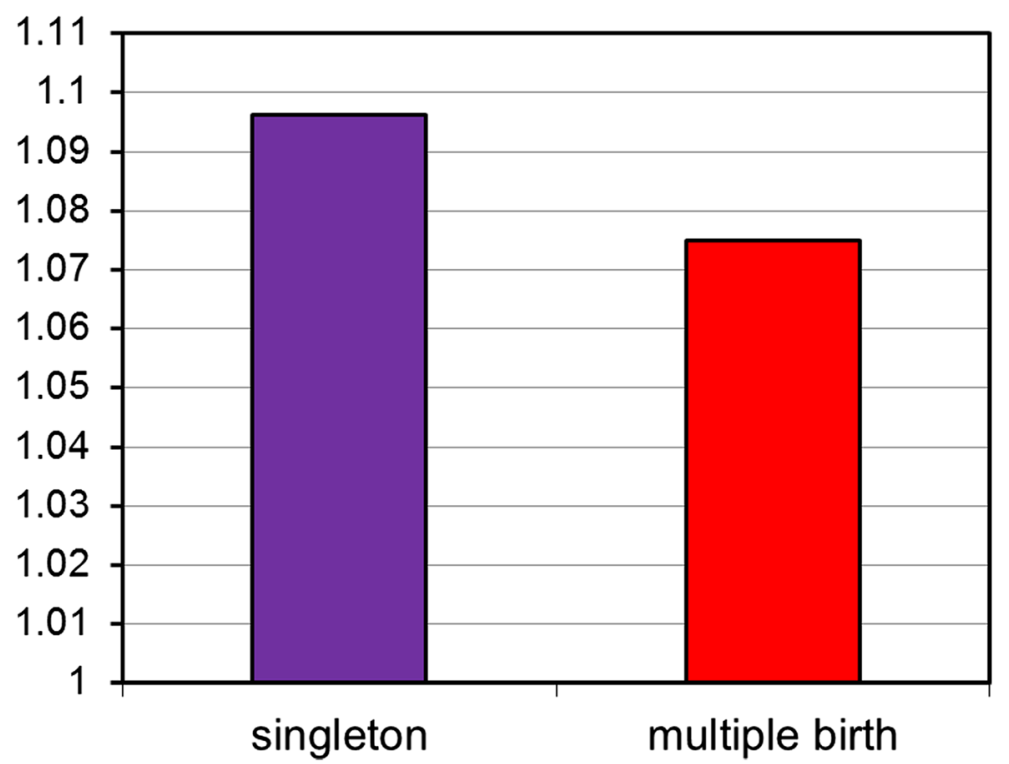

Fig. 2 Sex ratios by single and multiple births among 2,123,100 births 
amale $\quad$ female

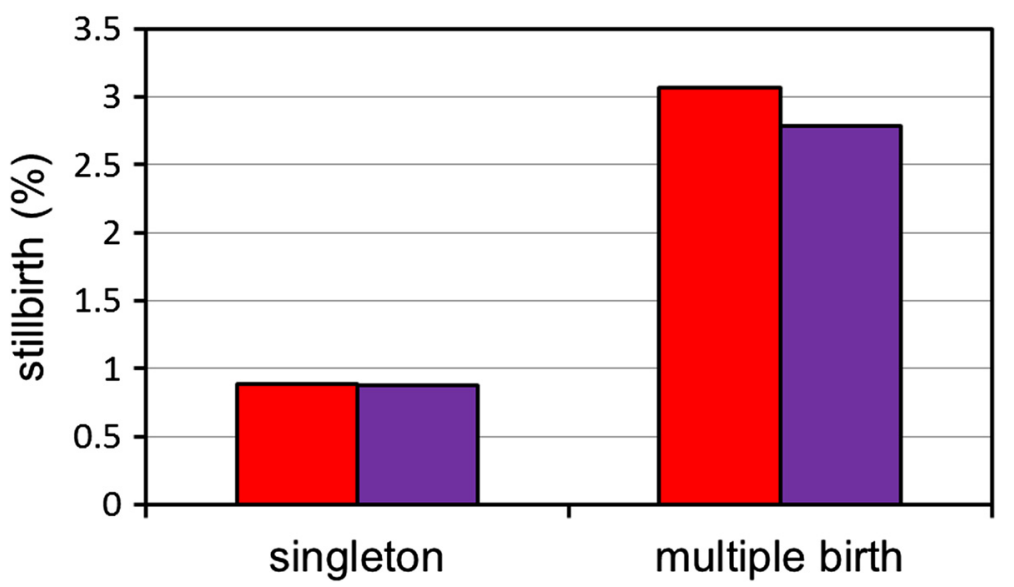

Fig. 3 Rates of stillbirths by sex at birth among 2,123,100 births

with an increase in the GA to the lowest level at GA $\geq 41$ weeks.

\section{Birth weight}

The sex ratio by birth weight is demonstrated in Fig. 4. There was a significant correlation of the sex ratio with birth weight $(p<0.001)$. The sex ratio was 0.846 at birth weight $<3000 \mathrm{~g}$, and then it rose proportionally with an increase in the birth weight to 1.922 (the highest) at birth weight $\geq 4000$ g.

Low birth weight infants were more common in females $(5.98 \%)$ than males $(4.71 \%)(p<0.001)$. The incidence of

Table 1 Gestational age (GA) in relation to sex ratio and neonatal outcomes among 1,973,767 singleton live births

\begin{tabular}{|c|c|c|c|c|c|c|c|c|c|c|c|}
\hline \multirow{2}{*}{$\begin{array}{l}\text { GA } \\
(w)\end{array}$} & \multicolumn{3}{|l|}{ Total } & \multicolumn{2}{|c|}{ Neonatal death } & \multicolumn{2}{|c|}{ Congenital anomaly } & \multicolumn{2}{|c|}{ Low birth weight } & \multicolumn{2}{|c|}{ Macrosomia } \\
\hline & Male $(n)$ & Female $(n)$ & Sex ratio & $\%$ & Sex ratio & $\%$ & Sex ratio & $\%$ & Sex ratio & $\%$ & Sex ratio \\
\hline$\leq 24$ & 804 & 666 & 1.207 & 77.48 & $1.320^{*}$ & 15.99 & 1.136 & 100 & 1.207 & 0.00 & - \\
\hline 25 & 386 & 285 & 1.354 & 47.24 & 1.331 & 5.07 & $0.700^{*}$ & 100 & 1.354 & 0.00 & - \\
\hline 26 & 455 & 316 & 1.440 & 31.00 & 1.276 & 4.67 & 1.118 & 100 & 1.440 & 0.00 & - \\
\hline 27 & 540 & 438 & 1.233 & 22.29 & 1.396 & 3.48 & 0.789 & 100 & 1.233 & 0.00 & - \\
\hline 28 & 683 & 534 & 1.279 & 14.71 & 1.594 & 3.12 & $0.652^{*}$ & 100 & 1.279 & 0.00 & - \\
\hline 29 & 791 & 580 & 1.364 & 9.34 & 1.909 & 2.70 & 0.947 & 100 & 1.364 & 0.00 & - \\
\hline 30 & 1145 & 881 & 1.300 & 5.92 & 1.400 & 2.86 & 1.148 & 99.70 & 1.298 & 0.00 & - \\
\hline 31 & 1405 & 1032 & 1.361 & 4.10 & 1.273 & 2.95 & 1.483 & 98.89 & 1.358 & 0.00 & - \\
\hline 32 & 2218 & 1581 & 1.403 & 2.21 & 1.270 & 2.47 & 1.410 & 95.97 & 1.408 & 0.00 & - \\
\hline 33 & 3388 & 2371 & 1.429 & 1.96 & 1.457 & 1.86 & 1.432 & 88.82 & $1.384^{*}$ & 0.00 & - \\
\hline 34 & 6298 & 4656 & 1.353 & 1.52 & 1.169 & 1.53 & $1.000^{*}$ & 72.08 & $1.222^{*}$ & 0.09 & 2.333 \\
\hline 35 & 14,090 & 10,293 & 1.369 & 0.78 & 1.436 & 1.22 & 1.339 & 44.89 & $1.084^{*}$ & 0.32 & 1.026 \\
\hline 36 & 42,246 & 31,262 & 1.351 & 0.35 & 1.421 & 0.79 & $1.750^{*}$ & 21.14 & $0.910^{*}$ & 0.64 & 1.597 \\
\hline 37 & 139,442 & 109,431 & 1.274 & 0.17 & 1.434 & 0.56 & $1.455^{*}$ & 7.61 & $0.740^{*}$ & 0.99 & $1.876^{*}$ \\
\hline 38 & 295,342 & 253,577 & 1.165 & 0.11 & $1.557^{*}$ & 0.45 & $1.521^{*}$ & 3.28 & $0.643^{*}$ & 1.45 & $2.173^{*}$ \\
\hline 39 & 291,920 & 279,557 & 1.044 & 0.09 & $1.309^{*}$ & 0.43 & $1.394^{*}$ & 1.73 & $0.536^{*}$ & 2.18 & $2.053^{*}$ \\
\hline 40 & 189,884 & 198,222 & 0.958 & 0.09 & 0.955 & 0.46 & $1.250^{*}$ & 0.96 & $0.521^{*}$ & 3.70 & $1.821^{*}$ \\
\hline 41 & 38,268 & 42,722 & 0.896 & 0.13 & 0.946 & 0.59 & $1.154^{*}$ & 0.69 & $0.508^{*}$ & 5.65 & $1.669^{*}$ \\
\hline$\geq 42$ & 2933 & 3125 & 0.939 & 0.25 & 1.143 & 0.79 & 1.000 & 1.29 & $0.560^{*}$ & 8.40 & $1.495^{*}$ \\
\hline Total & $1,032,238$ & 941,529 & 1.096 & 0.27 & $1.341^{*}$ & 0.53 & $1.379^{*}$ & 5.31 & $0.863^{*}$ & 2.17 & $1.922^{*}$ \\
\hline
\end{tabular}




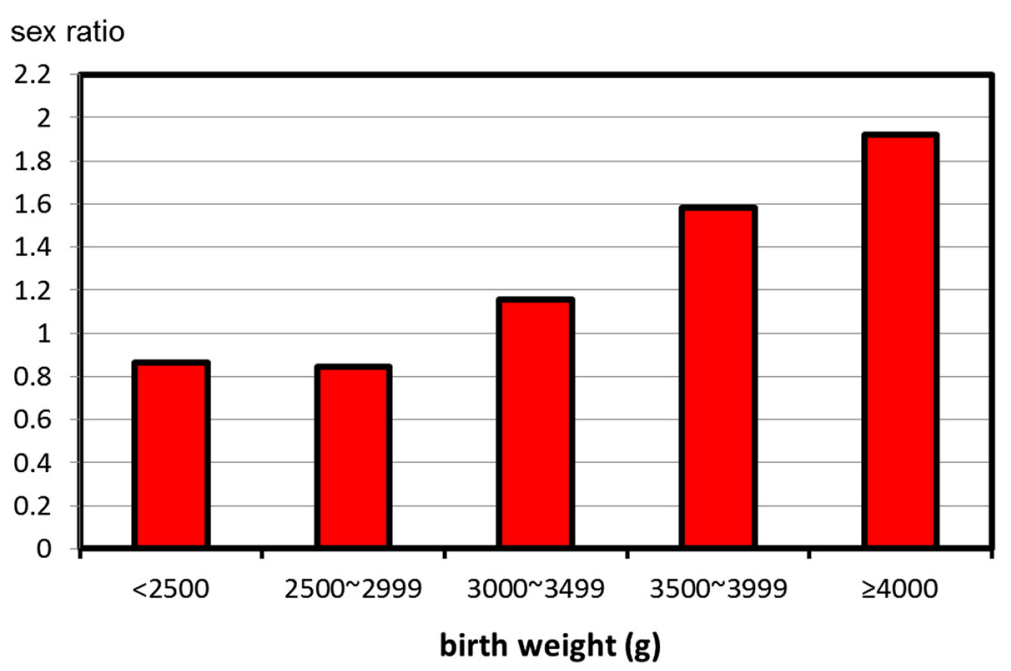

Fig. 4 Sex ratios by birth weight among 1,973,767 singleton live births

low birth weight infants declined from GA of 29 weeks (100\%) to the lowest level at GA of 41 weeks (0.69 \%), and then rose at GA of $\geq 42$ weeks (1.29 \%) (Table 1). In addition, there was a significant decrease in sex ratios of low birth weight infants among GA of $\geq 33$ weeks when compared with those without low birth weight.

Macrosomia was more common in males $(2.74 \%)$ than females $(1.56 \%)(p<0.001)$. The incidence of macrosomia increased proportionally from GA of 33 weeks (0\%) to the highest level at GA of $\geq 42$ (8.40\%) (Table 1). Furthermore, there was a significant increase in sex ratios of macrosomia among GA of $\geq 37$ weeks when compared with those without macrosomia.

\section{Neonatal death}

Overall, $68.7 \%$ of neonatal death occurred within 7 days of life (early neonatal death). There was an increasing risk of neonatal death among males compared to females, including early death and late death $(p<0.001)$. The sex ratio of neonatal death according to gestational age is illustrated in Fig. 5. When compared with neonatal survival, the sex ratios of early neonatal death were higher in GA of $\leq 24$ and 37 39 weeks $(p<0.001)$.

Overall, the incidence of neonatal death was $0.27 \%$ (Table 1). The incidence of neonatal death declined with an increase in the GA to the lowest level at GA of 40 weeks $(0.09 \%)$, and then increased to $0.25 \%$ at $\mathrm{GA} \geq 42$ weeks. In addition, there was a significant increase in sex ratios of neonatal death among GA of $\leq 24,38$ and 39 weeks than those without neonatal death.

\section{Congenital anomaly}

Congenital anomaly was more common in males $(0.58 \%)$ than females $(0.46 \%)(p<0.001)$. The incidence of congenital anomaly declined with an increase in the

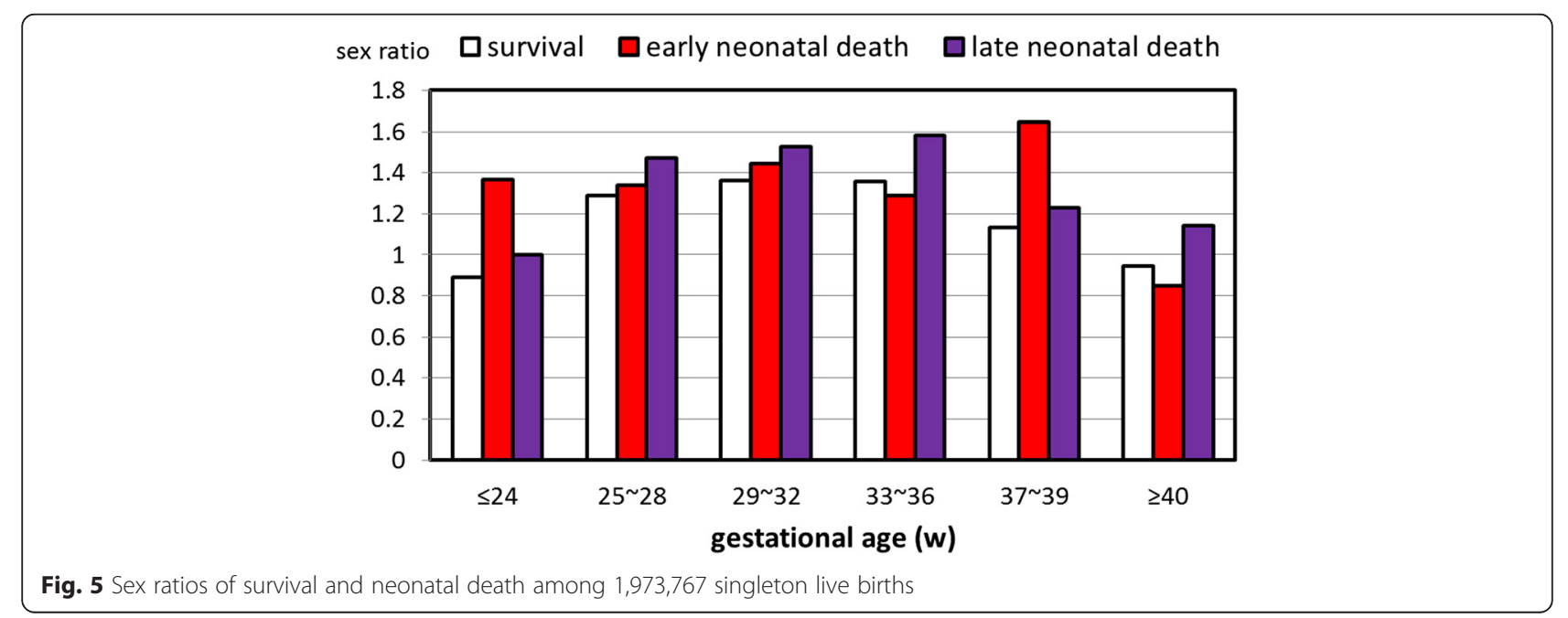


GA to the lowest level at GA of 39 weeks (0.43\%), and then gradually increased to $0.79 \%$ at GA $\geq 42$ weeks (Table 1). In addition, there was a significant increase in sex ratios of congenital anomaly among GA of 36 41 weeks than those without anomaly. In contrast, the sex ratios of congenital anomaly among GA of 25, 28 , and 34 weeks significantly decreased than those without anomaly.

The sex ratios were significantly higher for neonates with abnormality in the craniofacial $(p<0.05)$, urogenital $(p<0.001)$, and musculoskeletal $(p<0.001)$ systems (Fig. 6). In particular, the sex ratio of neonates with abnormal urogenital system was 4.72 times that of neonates without urogenital anomaly. Furthermore, there was a trend of anomaly in the digestive system among males than females $(p=0.053)$.

\section{Delivery mode}

CS was more common in males (33.2\%) than females $(31.6 \%)(p<0.001)$. In addition, the sex ratio of neonates with operative delivery (CS, forceps, and vacuum) was higher than that of neonates without operative delivery $(p<0.001)$. The sex ratio by operative vaginal delivery is further illustrated in Fig. 7. Among 1,333,589 vaginal deliveries, the sex ratio of vacuum deliveries was significantly higher than that of vaginal deliveries without the assistance of vacuum $(p<0.001)$. In addition, forceps were more often used in males than females $(p<0.001)$.

\section{Logistic regression analysis of birth outcome in relation to gender}

The multivariate logistic regression model showed significant differences in the following six outcomes-including preterm birth, macrosomia, low birth weight, neonatal death, CS, and congenital anomaly. Preterm birth $(\mathrm{OR}=1.498,95 \% \mathrm{CI}=1.478-1.517)$, macrosomia $(\mathrm{OR}=1.749,95 \% \mathrm{CI}=1.714-1.785)$, neonatal death $(\mathrm{OR}=1.231,95 \% \mathrm{CI}=1.182-1.280)$, $\mathrm{CS}(\mathrm{OR}=$ $1.056,95 \% \mathrm{CI}=1.050-1.063)$, and congenital anomaly $(\mathrm{OR}=1.280,95 \% \mathrm{CI}=1.230-1.331)$ were more common in males than females. In contrast, low birth weight infants were less common in males than females $(\mathrm{OR}=0.645,95 \% \mathrm{CI}=0.636-0.654)$.

\section{Discussion}

This study depicts that the sex differences are associated with neonatal outcomes, including GA, birth weight, neonatal death, congenital anomaly, and delivery mode. Our survey was based on a national population-based data registry between 2001 and 2010 to investigate the correlation of sex with neonatal outcomes. Our study eliminated high-risk pregnancy to avoid the possible bias from maternal factors. In addition, we used a logistic regression analysis to minimize the effects of confounders from neonatal factors. The data demonstrate that male gender is at greater risks for the following five neonatal outcomes: preterm birth, macrosomia, congenital anomaly, neonatal death, and operative delivery (CS, forceps delivery, or vacuum delivery).

First, our results indicate an increasing risk of preterm birth with male gender, which is similar with a couple of investigations $[16,17]$. In our study, we further extend their inquiry by demonstrating GA-specific risks of sex differences. There is evidence showing that males are more vulnerable than females to suffer from ambient stressors during fetal development $[4,22]$. Accordingly, we presume that preterm birth could be a subsequent outcome of males encountering fetal stress.

Second, macrosomia was more common in male neonates. In contrast, low birth weight was more common in female neonates. These findings are largely consistent with previous studies showing a higher risk of macrosomia and a low risk of small for GA among male infants

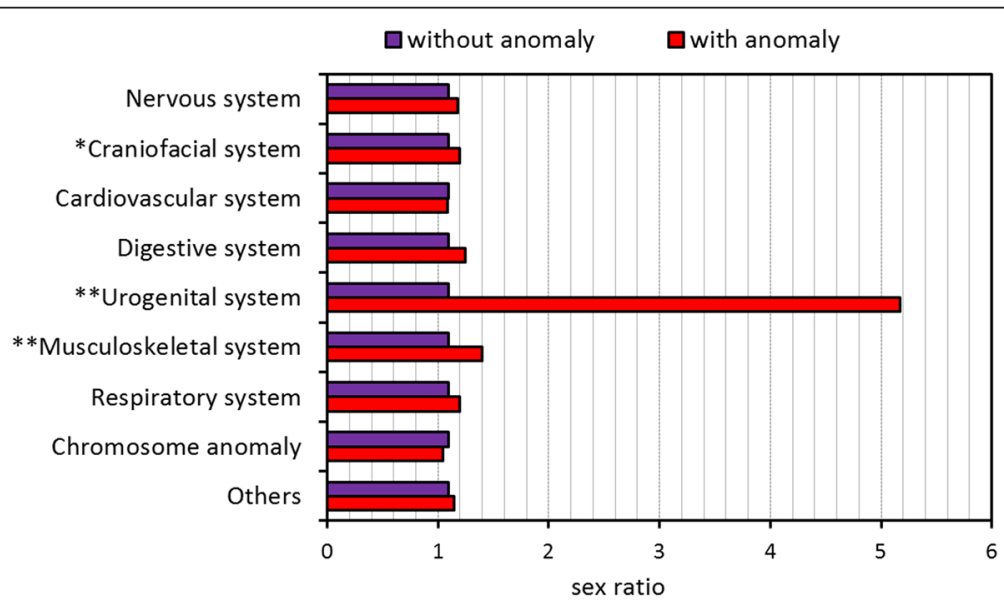

Fig. 6 Sex ratios of congenital anomalies among 1,973,767 singleton live births. ${ }^{*} p<0.05 .{ }^{* *} p<0.001$ 
without $\square$ with

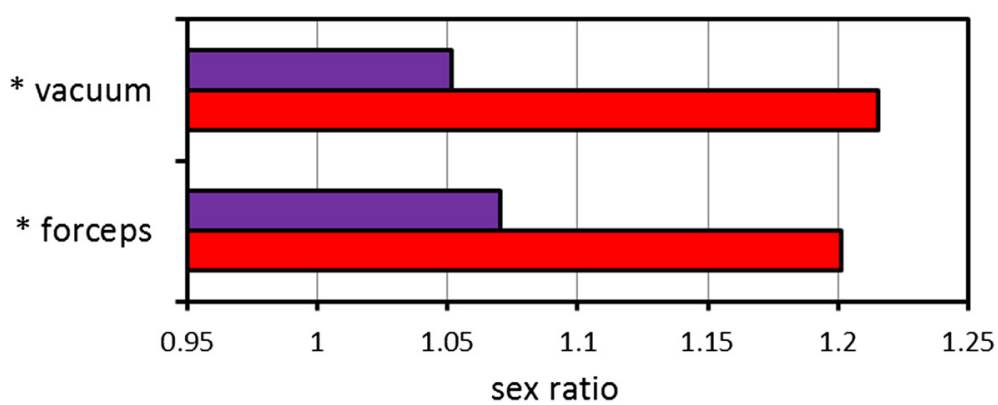

Fig. 7 Sex ratios of operative delivery among 1,333,589 singleton live births by vaginal delivery. ${ }^{*} p<0.001$

$[4,17,23]$. It is not a surprising fact because growth is faster in male than in female fetuses.

Third, male neonates possess a greater risk of congenital anomaly. Our study further illustrated that a greatest risk on urogenital anomaly, followed by the musculoskeletal and craniofacial systems. The findings were largely in accordance with a number of studies reporting an elevated risk of congenital anomalies in males [24-27].

Fourth, operative deliveries were more common in male neonates, which is consistent with many studies $[16,18,21,28,29]$. It is probably because a large fetal weight, such as macrosomia, is an indication of CS for difficult labor [16, 29, 30]. Nevertheless, our logistic regression model showed a significantly higher rate of CS in males after controlling for cofactors, including birth weight. We speculated that sociopolitical behaviors also play an important role in the gender difference with CS $[18,28]$. The preference for sons in Chinese parents may serve as the likely reason of CS [31], because they believe that the fate of their sons could be manipulated by the timing of birth via CS [32, 33].

Fifth, neonatal death was more common in males $[34,35]$. In specific, early neonatal death contributed to a majority of neonatal death. Furthermore, males with GA $\leq 24$ weeks carried higher risk of neonatal death, which is similar to a review showing that premature girls have better outcome than premature boys [36]. Delay of lung maturation among male fetuses may serve as an important factor to the sex difference in neonatal mortality [37]. In addition, our study demonstrated a greater risk of neonatal death among males at GA of 38 and 39 weeks. We suspected that, at least in part, congenital anomaly is associated with neonatal death of males [35].

Our study indicated that multiple births have a lower sex ratio than singletons, which was consistent with results from the previous studies [31, 38, 39]. In addition, we demonstrated a higher rate of stillbirths in males among multiple births. This finding was similar to those of previous studies which showed a greater risk for prenatal mortality among male fetuses [38, 40, 41]. The mechanism is probably due to multiple births being a significant stressor to male fetuses [22, 38], which will subsequently lead to stillbirth and a decline in the male birth number.

In our study, the sex ratio was higher than the average ratio in Western countries [2]. Selective abortion has been regarded as an important explanation for the skewed sex ratio in favor of males in some Asian countries, such as India and China [42-46]. However, an evidence-based study to prove this theory is lacking in Taiwan. In addition, the overall sex ratio at birth remained stable during the study period of 10 years, which is unlike a rising trend in the sex ratio in other Asian countries [31, 44, 47, 48]. The data suggest that, despite an unbalanced sex ratio at birth in Taiwan, the consequence of a preference for sons had only a slight effect.

There are limitations to this study. First, our study did not investigate the effects of assisted reproductive technologies. Nevertheless, there is no evidence to show any correlations of assisted reproductive technologies with the sex ratio in Taiwan $[49,50]$. Second, we were unable to take parental socioeconomic factors, such as educational level, into account in our analyses because the information was not available in our database. Third, our study did not control for environmental factors in relation to the sex ratio [51]. We believe that the influence was small, because Taiwan is an island with no significant changes in outer exposures. Accordingly, people living in Taiwan might share a similar environment. Fourth, we are not certain that the delivery protocols were exactly the same. In Taiwan, the National Health Insurance Administration covers the expenses of all deliveries. It has established clinical guideline for delivery. Thus, we believe the majority of protocols employed in this study should be similar. Despite those limitations, there are two major strengths of this study. First, our study used a large nationwide sample 
size to analyze the sex ratio in relation to neonatal birth outcomes. The birth registration data used in this study were shown to have a good validity and reliability in birth outcomes [52, 53]. Second, our population-based source offered the potential to examine sex differences across the entire spectrum of neonatal birth outcomes.

\section{Conclusions}

We identified male gender as an independent risk factor for adverse neonatal outcomes-including preterm birth, macrosomia, operative delivery, neonatal death, and congenital anomaly. The present study is consistent with the hypothesis that males are more vulnerable than females in the fetal environment. The data have clinical implications for health surveillance for plotting strategies in response to an unbalanced sex ratio. Parents with a preference for boys should take the greater risk of adverse neonatal outcomes with male gender into consideration.

\section{Abbreviations}

Cl: confidence intervals; CS: cesarean section; GA: gestational age; OR: odds ratio.

\section{Competing interests}

The authors declare that they have no competing interests.

\section{Authors' contributions}

YHW and YWC participated in data collection and the statistical analysis. All authors conceived and developed the study and drafted the manuscript. The final manuscript was read and approved by all authors.

\section{Acknowledgements}

This study was supported by research grants from the National Health Research Institutes (PH-101-PP-20) and Ministry of Science and Technology (NSC102-2511-S-038-005, MOST 104-2314-B-182A-138-, and MOST 104-2410H-038-006-SSS).

\section{Author details}

'Division of Neonatology, Department of Pediatrics, Chang Gung Memorial Hospital, Chang Gung University College of Medicine, 199 Dunhua North Road, Taipei 105, Taiwan. ${ }^{2}$ Department of Public Health, Kaohsiung Medical University, 100 Shih-Chuan 1st Road, Kaohsiung 80708, Taiwan. ${ }^{3}$ Master Program in Global Health and Development, Health Policy and Care Research Center, College of Public Health and Nutrition, Taipei Medical University, 250 Wu-Hsing Street, Taipei 110, Taiwan.

\section{Received: 21 August 2015 Accepted: 4 December 2015}

\section{Published online: 09 December 2015}

\section{References}

1. Pham BN, Hall W, Hill PS, Rao C. Analysis of socio-political and health practices influencing sex ratio at birth in Viet Nam. Reprod Health Matters. 2008;16(32):176-84.

2. Mathews TJ, Hamilton BE. Trend analysis of the sex ratio at birth in the United States. Natl Vital Stat Rep. 2005;53(20):1-17.

3. Pavic D. Factors affecting sex ratio at birth in Croatia 1998-2008. J Biosoc Sci. 2012:44(3):357-64.

4. Rueness J, Vatten L, Eskild A. The human sex ratio: effects of maternal age. Hum Reprod. 2012;27(1):283-7.

5. Garenne M. Poisson variations of the sex ratio at birth in African demographic surveys. Hum Biol. 2008:80(5):473-82.

6. Rosenfeld CS, Roberts RM. Maternal diet and other factors affecting offspring sex ratio: a review. Biol Reprod. 2004;71(4):1063-70.

7. Yang CY, Tsai SS, Cheng BH, Hsu TY, Wu TN. Sex ratio at birth associated with petrochemical air pollution in Taiwan. Bull Environ Contam Toxicol. 2000;65(1):126-31.
8. Gibson MA, Mace R. Strong mothers bear more sons in rural Ethiopia. Proc Biol Sci. 2003:270 Suppl 1:S108-9.

9. Song S. Does famine influence sex ratio at birth? Evidence from the 1959-1961 Great Leap Forward Famine in China. Proc Biol Sci. 2012;279(1739):2883-90.

10. Song S. Evidence of adaptive intergenerational sex ratio adjustment in contemporary human populations. Theor Popul Biol. 2014:92:14-21.

11. Helle S, Helama S, Lertola K. Evolutionary ecology of human birth sex ratio under the compound influence of climate change, famine, economic crises and wars. J Anim Ecol. 2009;78(6):1226-33.

12. Terrell ML, Hartnett KP, Marcus M. Can environmental or occupational hazards alter the sex ratio at birth? A systematic review. Emerg Health Threats J. 2011:4:7109.

13. Wallner B, Fieder $\mathrm{M}$, Seidler $\mathrm{H}$. Ownership of dwelling affects the sex ratio at birth in Uganda. PLoS One. 2012;7(12):e51463.

14. Maalouf WE, Mincheva MN, Campbell BK, Hardy IC. Effects of assisted reproductive technologies on human sex ratio at birth. Fertil Steril. 2014; 101(5):1321-5

15. Madan K, Breuning MH. Impact of prenatal technologies on the sex ratio in India: an overview. Genet Med. 2014;16(6):425-32.

16. Khalil MM, Alzahra E: Fetal gender and pregnancy outcomes in Libya: a retrospective study. Libyan J Med. 2013, 8 doi: 10.3402/ljm.v8i0.20008.

17. Sheiner E, Levy A, Katz M, Hershkovitz R, Leron E, Mazor M. Gender does matter in perinatal medicine. Fetal Diagn Ther. 2004;19(4):366-9.

18. Eogan MA, Geary MP, O'Connell MP, Keane DP. Effect of fetal sex on labour and delivery: retrospective review. BMJ. 2003;326(7381):137.

19. Weng YH, Yang CY, Chiu YW. Risk assessment of adverse birth outcomes in relation to maternal age. PLoS One. 2014;9(12):e114843.

20. Reddy UM, Laughon SK, Sun L, Troendle J, Willinger M, Zhang J. Prepregnancy risk factors for antepartum stillbirth in the United States. Obstet Gynecol. 2010;116(5):1119-26.

21. Hoa DT, Borjesson L, Nga NT, Johansson A, Malqvist M. Sex of newborns associated with place and mode of delivery: a population-based study in northern Vietnam. Genet Med. 2012;9(6):418-23.

22. Catalano R, Bruckner T, Anderson E, Gould JB. Fetal death sex ratios: a test of the economic stress hypothesis. Int J Epidemiol. 2005;34(4):944-8.

23. Melamed N, Yogev Y, Glezerman M. Fetal gender and pregnancy outcome. J Matern Fetal Neonatal Med. 2010;23(4):338-44.

24. Sokal R, Tata $L$, Fleming KM. Sex prevalence of major congenital anomalies in the United Kingdom: a national population-based study and international comparison meta-analysis. Birth Defects Res A Clin Mol Teratol. 2014;100(2):79-91.

25. Tennant PW, Samarasekera SD, Pless-Mulloli T, Rankin J. Sex differences in the prevalence of congenital anomalies: a population-based study. Birth Defects Res A Clin Mol Teratol. 2011;91(10):894-901.

26. Shaw GM, Carmichael SL, Kaidarova Z, Harris JA. Differential risks to males and females for congenital malformations among 2.5 million California births, 1989-1997. Birth Defects Res A Clin Mol Teratol. 2003:67(12):953-8.

27. Lary JM, Paulozzi LJ. Sex differences in the prevalence of human birth defects: a population-based study. Teratology. 2001;64(5):237-51.

28. Sheiner $\mathrm{E}$. The relationship between fetal gender and pregnancy outcome. Arch Gynecol Obstet. 2007;275(5):317-9.

29. Viegas OA, Lee PS, Lim KJ, Ravichandran J. Male fetuses are associated with increased risk for cesarean delivery in Malaysian nulliparae. Medscape J Med. 2008;10(12):276.

30. Sheiner E, Shoham-Vardi I, Silberstein T, Hallak M, Katz M, Mazor M. Failed vacuum extraction. Maternal risk factors and pregnancy outcome. J Reprod Med. 2001;46(9):819-24.

31. Tse WC, Leung KY, Hung BK. Trend of sex ratio at birth in a public hospital in Hong Kong from 2001 to 2010. Hong Kong Med J. 2013;19(4):305-10.

32. Lo JC. Patients' attitudes vs. physicians' determination: implications for cesarean sections. Soc Sci Med. 2003;57(1):91-6.

33. Hsu KH, Liao PJ, Hwang CJ. Factors affecting Taiwanese women's choice of Cesarean section. Soc Sci Med. 2008:66(1):201-9.

34. Titaley CR, Dibley MJ, Agho K, Roberts CL, Hall J. Determinants of neonatal mortality in Indonesia. BMC Public Health. 2008:8:232.

35. Alonso V, Fuster V, Luna F. Causes of neonatal mortality in Spain (1975-98): influence of sex, rural-urban residence and age at death. J Biosoc Sci. 2006; 38(4):537-51.

36. Glass HC, Costarino AT, Stayer SA, Brett CM, Cladis F, Davis PJ. Outcomes for extremely premature infants. Anesth Analg. 2015;120(6):1337-51. 
37. Khoury MJ, Marks JS, McCarthy BJ, Zaro SM. Factors affecting the sex differential in neonatal mortality: the role of respiratory distress syndrome. Am J Obstet Gynecol. 1985;151(6):777-82.

38. Jacobsen R, Moller H, Mouritsen A. Natural variation in the human sex ratio. Hum Reprod. 1999;14(12):3120-5.

39. Pollard GN. Factors influencing the sex ratio at birth in Australia, 1902-65. J Biosoc Sci. 1969;1(2):125-44.

40. Rydhstrom $\mathrm{H}$. The effects of maternal age, parity, and sex of the twins on twin perinatal mortality. A population based study. Acta Genet Med Gemellol. 1990;39(3):401-8.

41. Zahalkova M. Perinatal and infant mortality in twins. Prog Clin Biol Res. 1978;24(Pt B):115-20.

42. Sahni M, Verma N, Narula D, Varghese RM, Sreenivas V, Puliyel JM. Missing girls in India: infanticide, feticide and made-to-order pregnancies? Insights from hospital-based sex-ratio-at-birth over the last century. PLoS One. 2008; 3(5):e2224.

43. George SM. Millions of missing girls: from fetal sexing to high technology sex selection in India. Prenat Diagn. 2006;26(7):604-9.

44. Hesketh T, Xing ZW. Abnormal sex ratios in human populations: causes and consequences. Proc Natl Acad Sci U S A. 2006;103(36):13271-5.

45. Miller BD. Female-selective abortion in Asia: patterns, policies, and debates Am Anthropol. 2001:103(4):1083-95.

46. Wu Z, Viisainen $\mathrm{K}$, Hemminki E. Determinants of high sex ratio among newborns: a cohort study from rural Anhui province. China Reprod Health Matters. 2006;14(27):172-80.

47. Jha P, Kesler MA, Kumar R, Ram F, Ram U, Aleksandrowicz L, et al. Trends in selective abortions of girls in India: analysis of nationally representative birth histories from 1990 to 2005 and census data from 1991 to 2011. Lancet. 2011:377(9781):1921-8.

48. Guilmoto CZ, Hoang $X$, Van TN. Recent increase in sex ratio at birth in Viet Nam. PLoS One. 2009:4(2):e4624.

49. Chen LC, Chen CY, Horng HC, Yen MS, Wang PH, Chen CP, et al. Sex ratio at a tertiary medical center in northern Taiwan - an analysis of amniocentesis. Taiwan J Obstet Gynecol. 2014;53(1):118-9.

50. Lee IW, Lai YC, Kuo PL, Chang CM. Human sex ratio at amniocentesis and at birth in Taiwan. Taiwan J Obstet Gynecol. 2012;51 (4):572-5.

51. Yang CY, Cheng BH, Tsai SS, Wu TN, Hsu TY, Lin KC. Chlorination of drinking water and sex ratio at birth in Taiwan. J Toxicol Environ Health A. 2000;60(7):471-6.

52. Lin CM, Lee PC, Teng SW, Lu TH, Mao IF, Li CY. Validation of the Taiwan Birth Registry using obstetric records. J Formos Med Assoc. 2004;103(4):297-301.

53. Hwang BF, Jaakkola JJ. Risk of stillbirth in the relation to water disinfection by-products: a population-based case-control study in Taiwan. PLoS One. 2012;7(3):e33949.

\section{Submit your next manuscript to BioMed Central and we will help you at every step:}

- We accept pre-submission inquiries

- Our selector tool helps you to find the most relevant journal

- We provide round the clock customer support

- Convenient online submission

- Thorough peer review

- Inclusion in PubMed and all major indexing services

- Maximum visibility for your research

Submit your manuscript at www.biomedcentral.com/submit

) Biomed Central 